\author{
Darryl O'Callaghan \\ Anthony Holley \\ Jeffrey Lipman
}

\section{From the intensive care bed....we need to hear and listen}

Received: 11 December 2014

Accepted: 13 December 2014

Published online: 23 January 2015

(C) Springer-Verlag Berlin Heidelberg and ESICM 2015

D. O'Callaghan

Brisbane, Australia

A. Holley · J. Lipman (区)

Department of Intensive Care Medicine, Royal Brisbane and Women's Hospital, Brisbane, QLD 4029, Australia e-mail: anthony.holley@health.qld.gov.au

Tel.: +61 73646.8111

A. Holley $\cdot$ J. Lipman

Burns, Trauma, and Critical Care Research Centre, The University of Queensland, Herston, Brisbane, QLD 4029, Australia

\section{Case history}

Darryl, a 46-year-old businessman, was riding a motorcycle that collided at high speed with a trailer being towed by a utility vehicle. He arrived at our institution, a level I trauma centre, with profound haemodynamic instability and a positive focused abdominal ultrasound scan, and was immediately transferred to the operating theatre. In the operating theatre, he was found to have a right atrial appendage tear requiring urgent repair, bilateral massive retroperitoneal haematomas related to his open book pelvic fracture, which were packed, and a liver contusion with a capsular tear treated conservatively. Darryl also sustained a complex wound communicating directly with his sacrum. Other injuries included extensive rib fractures of his right hemithorax with underlying severe pulmonary contusion and a large right haemothorax. His initial damage control surgery was complemented by damage control resuscitation that included a massive blood transfusion. In the intensive care unit, his APACHE II score was subsequently determined to be 36 . So began Darryl's 35-day intensive care admission. This is Darryl's story that every intensive care physician must read.

\section{From the intensive care bed...}

My first recollection of ICU was hearing an ICU doctor say 'welcome back'. I had been in an induced coma for nearly 3 weeks. The day of the accident, doctors told my wife I had less than a $1 \%$ chance of survival. It was nothing short of a medical miracle I was still alive!

I spent 5 weeks in ICU fighting for my life, 2 of those while conscious, albeit very dazed. During those 2 weeks, I endured and witnessed the many challenges faced by an ICU patient.

The daily ritual of the consultant swinging by with his entourage was an experience. I was saturated with drugs but could still hear and see. The consultant would start out by standing at the end of my bed and saying "Mr O'Callaghan is an MBA", before talking about my injuries and treatment. This same process took place each day, and each day I would ask myself, why does he always start out by referring to my MBA (Masters in Business Administration)? Maybe my professional qualifications placed me at the front of the queue in terms of treatment? This must be the explanation, otherwise why would he keep talking about it? Let me tell you, given that interpretation, I was bloody glad I had an MBA. It was only sometime later I discovered MBA to be a motor bike accident!

The confusion I experienced over the "MBA" is just one of many misinterpretations I made while in ICU. The problem occurred because doctors rarely engaged with me, the patient, but yet I was the one about whom they talking. I was intubated and could not communicate, but I 
could see and hear. I was often left to generate my own interpretation which was clearly fraught with danger. I could have easily translated the consultant's comment about being immobilised into something far more distressing, such as being permanently paralysed.

In my opinion, the "soft skills" of good communication are critical in the care of a patient. I believe the patient should be the first port of call for the doctor when they arrive bedside. Firstly, to reassure the patient with comforting words, and then to briefly explain (after careful consideration of the content and the patient's mental state), in layman's terms, the patient's current condition and planned treatment.

Receiving poorly delivered information or having to make one's own interpretation in a sleep-deprived, drug haze leads to unnecessary anxiety....and just for clarity, the patient's head is at the top of the bed not the end.

Water, water everywhere, yet not a drop to drink! I had been intubated for several weeks, with not a molecule of water passing down my parched throat. Apart from escaping ICU, all I thought about day and night was water. I consistently ran a high fever and that, combined with being intubated, made it psychologically torturous to be unable to drink water. My critical care nurses would arrive alongside my bed to type up their notes on the computer, and what should they bring along... a bottle of crystal clear water! So message here is: don't take your water bottle near a conscious intubated patient, it amounts to psychological torture.

Time, time and more time! I was totally immobilised in my intensive care bed. My body was seriously broken, with only my eyes and ears providing reliable information. While I could still see, it wasn't necessarily a blessing. I have mentioned the distress induced by the sight of water, but that was not the only visual torture. In my ICU cubicle was a suspended clock staring straight back at me. If you want to know how long a minute is, let me confirm it's a lot longer than 60 seconds. When all you can do is lay in bed staring at a clock, every second feels like an hour and every minute feels like a day. Give strong consideration to removing those bloody clocks!

One of the biggest ironies for me in ICU is that it is supposed to represent intensive care. For the novice like me, I would expect it to be the ideal place to sleep. Wrong. Running a high fever all of the time made it incredibly difficult for me to sleep. My body felt like it was trying to shed its outer skin to escape the tumultuous battle raging within. I was desperate for sleep, but just not sleep...restful sleep. With the fever and drugs, every time
I closed my eyes I would start to have nightmares. With my body fighting fever and my mind fighting bad images, I would wake from my sleep often feeling worse. Fever and nightmares were not the only challenge. An ICU never sleeps; it operates $24 \times 7$. The lights are always on, people are always moving around. If I got four hours sleep in a day, it was a good day. Everyone knows the effect of sleep deprivation on a healthy individual. Apply that to someone who is fighting for their life, and then compound the effect on a daily basis and it quickly escalates to another form of torture. When you can't get at least $8 \mathrm{~h}$ of decent sleep, you have to endure far more minutes watching that clock. Please...someone find a way for an ICU patient to have natural sleep.

Transition nightmare. When I finally got the all clear to move to the ward, I thought it was the greatest day of my life...I was so very wrong. In the space of 10 minutes, I went from having a nurse by my bed 24 hours a day and wired to "Starship Enterprise" in the form of advanced monitoring equipment, to a private room with no one except me and one small heart rate monitor. I was terrified, isolated and endured tremendous anxiety worrying whether the ward nurses would respond quickly enough in the event I deteriorated. In a very short period of time, my level of care had significantly declined, yet my condition had not significantly improved. An easier transition from ICU to the ward would have done wonders for my mental health. My suggestion, particularly for long-stay ICU patients, is to consider an ICU nurse visiting the newly transferred patient in the ward every couple of hours for the first day or two.

Intensive care played a crucial role in saving my life, for which I will always be indebted to those dedicated medical and nursing folk who cared for me. Thanks to them, I have a second chance at life. My sincere hope is that, by sharing my story of the gruelling journey I underwent as an ICU patient, ICU teams may reconsider the way they treat patients, with the goal being to reduce, if not eliminate, the burden of fear, discomfort and misunderstanding continually faced by an ICU patient.

"Time is not the great teacher. Experience is. A man may live a whole life, but if he never leaves his home to experience that life, he dies knowing nothing. A mere child who has suffered and lived can be the wiser of the two."

Conflicts of interest The authors declare that they have no conflict of interest. 